American Journal of Pharmaceutical Education 2019; 83 (10) Article 7501.

\title{
BRIEF
}

\section{Faculty Perceptions of Entrustable Professional Activities to Determine Pharmacy Student Readiness for Advanced Practice Experiences}

\author{
Kali M. VanLangen, PharmD, Lisa Meny, PharmD, David Bright, PharmD, Mandy Seiferlein, MPA \\ Ferris State University, College of Pharmacy, Grand Rapids, Michigan \\ Submitted December 27, 2018; accepted March 28, 2019; published December 2019.
}

Objective. To quantify pharmacy faculty members' perceptions of the importance of entrustable professional activities (EPAs) and the expected level of entrustment that should be achieved to determine APPE readiness.

Methods. Entrustable professional activities define the core skills and tasks expected of new pharmacy graduates and may serve as a logical framework for determining pharmacy student readiness to begin advanced pharmacy practice experiences (APPEs). A five-question survey was distributed to all faculty members, staff members, and administrators at Ferris State University College of Pharmacy. Respondents were asked to rate 18 statements mapped to 12 EPAs on the perceived importance of each statement and the expected level of entrustment students should achieve to determine readiness for APPEs. Thresholds were used to determine consensus for importance and level of entrustment for each statement.

Results. Of the 44 faculty members surveyed, 28 (63.6\%) responded. A strong consensus was reached on the level of importance for 16 of 18 statements (89\%), while two statements demonstrated moderate consensus (11\%). No strong consensus was identified on levels of entrustment. Seven (39\%) of 18 statements demonstrated moderate entrustment consensus and $11(61 \%)$ statements demonstrated little consensus.

Conclusion. Strong consensus was identified regarding which EPAs are important to determine students' APPE readiness; however, no strong consensus was found when evaluating levels of entrustment. Lack of consensus regarding entrustment raises several questions that require further study and clarification as the implementation of EPAs continues throughout the Academy.

Keywords: entrustable professional activities, APPE readiness, assessment, pharmacy curriculum

\section{INTRODUCTION}

The Accreditation Council for Pharmacy Education (ACPE) Standards 2016 emphasize the need for students to not only demonstrate practice readiness upon graduation, but also readiness to enter advanced pharmacy practice experiences (APPEs). ${ }^{1}$ The standards require schools and colleges of pharmacy to define performance levels that students must achieve prior to the start of APPEs. Standard 25.8 states, "the Pre-APPE curriculum leads to a defined level of competence in professional knowledge, knowledge application, patient and population-based care, medication therapy management skills, and the attitudes important to success in the advanced experiential program. Competence in these areas is assessed prior to the first APPE." "These knowledge,

Corresponding Author: Kali VanLangen, Ferris State

University College of Pharmacy, 25 Michigan St., Ste. 7000, Grand Rapids, MI 49503. Tel: 616-685-6676. E-mail:

KaliVanLangen@ferris.edu skills, and attitudes should be expected of all students on day one of their first APPE. Matriculation through the didactic curriculum alone does not meet the intent of the standards. Even with the specific expectations listed within the standards, literature describing methods to assess APPE readiness is sparse and no consistent approach to determine APPE readiness has emerged. Therefore, it may be necessary to identify specific criteria or assessments to serve mechanisms to ensure students are ready for APPEs.

The discussion of specific criteria was further expanded in the Standards 2016 Guidance, with a notation that schools and colleges of pharmacy should identify professional activities that graduates perform routinely. ${ }^{2}$ In response, the American Association of Colleges of Pharmacy (AACP) Academic Affairs Standing Committee developed a set of core entrustable professional activities (EPAs) for the profession of pharmacy. ${ }^{3,4}$ The EPAs are "units of professional practice, defined as tasks 


\section{American Journal of Pharmaceutical Education 2019; 83 (10) Article 7501.}

or responsibilities that trainees are entrusted to perform unsupervised once they have attained sufficient specific competence." ${ }^{4}$ While the Center for Advancement of Pharmaceutical Education (CAPE) 2013 Educational Outcomes $^{5}$ and Standards $2016^{1}$ encompass the individual components of EPAs, the explicit EPA statements articulate the professional activities of practicing pharmacists. Therefore, EPAs create a framework to define practice readiness.

If EPAs are an appropriate framework for assessing practice readiness, backward curriculum design justifies the consideration of EPAs as a framework for assessing APPE readiness. ${ }^{6}$ The EPA framework establishes both specific skills and tasks, as well as a scale for the expected level of entrustment. The levels of entrustment (Table 1) range from solely observing (Level I) to supervising more junior colleagues (Level V). Literature suggests that upon graduation, students should be capable of performing skills and tasks with reactive supervision (Level III) at minimum. ${ }^{3}$

By working from the desired product of the PharmD curriculum, ie, a practice-ready pharmacist, a determination should be made as to where students need to be prior to APPEs in order to be on track to achieve these competencies. ${ }^{7}$ To our knowledge, there has not been a nationwide assessment as to whether EPAs have been uniformly accepted, or whether modifications (ie, adding or deleting EPA statements) when adopting the Core EPAs are common. Anecdotally, evidence exists that there may be a lack of uniformity across different schools of pharmacy with regards to the process of EPA implementation and integration.

We recognized that there are two constructs that needed to be considered when evaluating the use of EPAs for APPE readiness: the level of importance of the EPA in determining APPE readiness and the level of entrustment that the student should possess. The purpose of this paper is to quantify faculty perceptions of EPA importance and the expected level of entrustment that should be achieved to determine readiness to enter APPEs.

\section{METHODS}

A link to an online survey developed in QuestionPro (QuestionPro, Inc, San Francisco, CA), was distributed to the Ferris State University College of Pharmacy (FSU) faculty, staff, and administrators via email in August 2017, with a corresponding announcement made during a monthly college-wide meeting. A follow-up reminder was sent one week after the initial survey request to encourage participation. The survey was open for two weeks.

To assist with orienting survey respondents to various terms within the survey, definitions were provided. The term "APPE-ready" was described as, "students being ready to enter advanced pharmacy practice experiences (Block A)." "Block A" is the first scheduled APPE following completion of the didactic curriculum. "Practice-ready" was described as, "being ready to provide entry-level direct patient care in a variety of healthcare settings." Levels of entrustment were also defined (Table 1). Additionally, FSU has adopted the Core EPAs as published, with the addition of a 16th EPA related to development of leadership skills. ${ }^{4}$ Pharmacy schools are not required to use the Core EPAs verbatim, which offers the opportunity for schools to customize EPA offerings to their needs. ${ }^{8}$ For uniformity with others that have adopted the Core EPAs as proposed, the scope of this paper was limited to the 15 Core EPAs.

A five-question survey was developed that included 18 unique statements that were adapted from Riskin and colleagues. ${ }^{9}$ These statements were selected as key examples of supporting tasks of the Core EPAs. Additionally, they provided greater context for professionalism and communication, which are foundational to the Core EPAs. The first question instructed respondents to rate how important they believed each of the 18 core

Table 1. Descriptions of Levels of Entrustment for Core Entrustable Professional Activities

\begin{tabular}{lc}
\hline Level & Description \\
\hline Level I - Observes only & Learner observes only. \\
Level II - Direct supervision & $\begin{array}{c}\text { Learner performs task with direct supervision and frequent } \\
\text { feedback or correction. } \\
\text { Level III - Reactive supervision }\end{array}$ \\
Level IV - Intermittent supervision & self-directed and seeks guidance PRN. \\
Level V - General direction & supervision \\
& Learner has mastered the task. Student supervises and is \\
& qualified to give meaningful feedback to other learners.
\end{tabular}

Abbreviations: $\mathrm{PRN}=$ as needed 


\section{American Journal of Pharmaceutical Education 2019; 83 (10) Article 7501.}

pharmacist task statements were in determining whether a student was ready to enter APPEs; in other words, the degree to which they believed each statement was relevant for determining APPE readiness. Respondents selected their perceived level of importance of each statement from a four-point Likert-type scale, although they could select a fifth option of "unable to rate," and responses were not required. When applicable, each of the 18 statements were mapped to the appropriate EPA and resulted in the mapping of 12 EPAs because they are taught and summatively assessed in the pre-APPE curriculum; the remaining three EPAs (EPA numbers 5, 12, 13) are taught throughout P1-P4 years, but are only summatively assessed during APPEs (Table 2). As the survey was intended to measure the opinion, beliefs, and attitudes of the respondents, Likert-type scaling was deemed an appropriate item format. ${ }^{10}$

The second question used the same 18 statements and asked faculty members to rate the level of entrustment they expected a student to have before beginning APPEs. The response options were the five levels of entrustment (represented in a Likert-type scale), along with an additional option of "not applicable" (Table 1). The remaining three questions were directed at internal qualityimprovement issues and lacked external applicability. Therefore, this study focused only on the results of the first two questions, ie, importance and entrustment.

The FSU uses a consistent threshold approach to present assessment and related data to the faculty. To be consistent with this approach for the benefit of faculty engagement with the data, consensus thresholds were established to describe the level of importance and level of entrustment (Table 3). For the purposes of summarizing the data collected for each statement, the top two Likert-type scale responses (very important and moderately important) were collapsed and the bottom two Likert-type scale responses (slightly important and not important) were collapsed to create a dichotomous view of the results. Collapsing the Likert-type scale responses into a dichotomous measure allowed for a simplified comparison of respondent beliefs about each statement as a measure of APPE readiness. Specifically, they either believed it was important or they believed it was of little or no importance. This method of collapsing the Likerttype scale responses according to directionality is supported for purposes of interpretation of results and is

Table 2. FSU Entrustable Professional Activity Summative Assessment Curriculum Map

\begin{tabular}{|c|c|c|c|c|}
\hline \multirow[b]{2}{*}{ Entrustable Professional Activity } & \multicolumn{4}{|c|}{ Professional Year } \\
\hline & $\mathbf{P 1}$ & $\mathbf{P 2}$ & $\mathbf{P 3}$ & P4 \\
\hline $\begin{array}{l}\text { EPA 1: Collect information to identify a patient's medication related } \\
\text { problems and health-related needs. }\end{array}$ & $\mathrm{X}$ & $\mathrm{X}$ & $\mathrm{X}$ & $\mathrm{X}$ \\
\hline $\begin{array}{l}\text { EPA 2: Analyze information to determine the effects of medication } \\
\text { therapy, identify medication-related problems, and prioritize health- } \\
\text { related needs (including immunizations). }\end{array}$ & & $\mathrm{X}$ & $\mathrm{X}$ & $\mathrm{X}$ \\
\hline $\begin{array}{l}\text { EPA 3: Establish patient-centered goals and create a care plan for a patient } \\
\text { in collaboration with the patient, caregiver(s), and other health } \\
\text { professionals that is evidence-based and cost-effective. }\end{array}$ & $\mathrm{X}$ & $\mathrm{X}$ & $\mathrm{X}$ & $X$ \\
\hline $\begin{array}{l}\text { EPA 4: Implement a care plan in collaboration with the patient, caregivers, } \\
\text { and other health professionals. }\end{array}$ & & $\mathrm{X}$ & $\mathrm{X}$ & $\mathrm{X}$ \\
\hline EPA 5: Follow-up and monitor a care plan. & & & & $\mathrm{X}$ \\
\hline EPA 6: Collaborate as a member of an interprofessional team. & & $\mathrm{X}$ & $\mathrm{X}$ & $\mathrm{X}$ \\
\hline EPA 7: Identify patients at risk for prevalent diseases in a population. & $\mathrm{X}$ & $\mathrm{X}$ & $\mathrm{X}$ & $\mathrm{X}$ \\
\hline EPA 8: Minimize adverse events and medication errors. & & $\mathrm{X}$ & & $\mathrm{X}$ \\
\hline EPA 9: Maximize the appropriate use of medications in a population. & & $\mathrm{X}$ & & $\mathrm{X}$ \\
\hline $\begin{array}{l}\text { EPA 10: Ensure that patients have been immunized against vaccine- } \\
\text { preventable diseases }\end{array}$ & $\mathrm{X}$ & $\mathrm{X}$ & $\mathrm{X}$ & $\mathrm{X}$ \\
\hline $\begin{array}{l}\text { EPA 11: Educate patients and professional colleagues regarding the } \\
\text { appropriate use of medications. }\end{array}$ & $\mathrm{X}$ & $\mathrm{X}$ & $\mathrm{X}$ & $\mathrm{X}$ \\
\hline EPA 12: Use evidence-based information to advance patient care. & & & & $\mathrm{X}$ \\
\hline EPA 13: Oversee the pharmacy operations for an assigned work shift. & & & & $X$ \\
\hline EPA 14: Fulfill a medication order. & $\mathrm{X}$ & $\mathrm{X}$ & $\mathrm{X}$ & $\mathrm{X}$ \\
\hline EPA 15: Create a written plan for continuous professional development. & $\mathrm{X}$ & $\mathrm{X}$ & $\mathrm{X}$ & $\mathrm{X}$ \\
\hline EPA 16: Lead a project, organization, team or event. & $\mathrm{X}$ & $\mathrm{X}$ & $\mathrm{X}$ & $\mathrm{X}$ \\
\hline
\end{tabular}

Abbreviations: EPA = Entrustable Professional Activity 


\section{American Journal of Pharmaceutical Education 2019; 83 (10) Article 7501.}

generally accepted to have little, if any, impact on the validity or reliability of the findings. ${ }^{11}$ Threshold criteria described in Table 3 were then applied to these dichotomous results to arrive at the overall consensus among the respondents on the level of importance for each statement (strong consensus, moderate consensus, little consensus). Additionally, a rank order was produced by ordering the percentage score of "very important/moderately important" for each statement. Percentage score ties were ranked by giving a higher ranking to the statement with a higher number of "very important" ratings relative to "moderately important" ratings. The Ferris State University Institutional Review Board (IRB) determined that this research did not meet the federal definition of human subjects research and was therefore deemed exempt.

\section{RESULTS}

Forty-four faculty members were invited to participate in the survey, of which 28 elected to participate (63.6\%). Although the survey was administered to all faculty members, staff members, and administrators, a low response rate from administrators $(n=1)$ and staff members $(n=0)$ prompted the decision to eliminate the one administrator's response from the data set and solely report the faculty responses. The majority of respondents were PharmD/practice faculty members $(78.6 \%$ of all respondents, $\mathrm{n}=22$ ), followed by $\mathrm{PhD} /$ science faculty members $(21.4 \%$ of all respondents, $n=6)$. The majority of respondents $(55.17 \%)$ reported teaching primarily in the third professional year of the program, followed by $27.6 \%$ in the first professional year, and $13.8 \%$ in the second professional year. In terms of educational training, $89.3 \%(n=25)$ of respondents were licensed pharmacists. Of these, $88 \%(n=22)$ had earned a PharmD and $12 \%$ $(n=3)$ had earned a BS in pharmacy. Faculty respondents who precepted direct patient care APPEs practiced in the following areas: inpatient medicine $(41.2 \%, \mathrm{n}=7)$, ambulatory medicine $(35.3 \%, \mathrm{n}=6)$, both inpatient and ambulatory medicine $(5.9 \%, \mathrm{n}=1)$, and electives $(17.6 \%$, $\mathrm{n}=3$ ). For each of the 18 statements describing core pharmacist tasks to determine APPE readiness, respondents were asked to rate the two major constructs of importance and entrustment. Respondents' reported levels of importance and entrustment were collected and thresholds for consensus levels applied to summarize the overall perceptions of the faculty.

Respondents were instructed to rate how important they believed each of the 18 core pharmacist task statements were in determining if a student was ready to enter APPEs. A ranking of the 18 statements according to the degree of consensus is included in Table 4. Overall, a strong consensus was reached on 16 of the 18 statements. Of the 16 strong consensus statements, six statements received zero responses of slightly important/not important, indicating that $100 \%$ of faculty members were in agreement that these items were most important. A moderate consensus was reached on two of the statements.

Conversely, of the 18 statements assessed for level of entrustment to enter APPEs, no strong consensus was ascertained. A moderate consensus was reached on seven of the statements, while little consensus was reached on the remaining 11 statements. The overall consensus results for levels of entrustment reported for each statement by the respondents is summarized in Table 5, along with the most frequently selected response. Of the 18 statements, 10 resulted in a median rating of a Level 3 entrustment. Additionally, 15 of the 18 statements spanned at least four of the five entrustment levels.

\section{DISCUSSION}

This paper describes a preliminary assessment of faculty perceptions of both importance and level of entrustment of EPAs as a metric to assess APPE readiness. Professional behaviors, including participation and preparation, ranked highest among faculty members. This

Table 3. Pre-Determined Consensus Thresholds for Levels of Importance and Entrustment

\begin{tabular}{lcc}
\hline & \multicolumn{1}{c}{ Level of Importance } & $\begin{array}{c}\text { Level of } \\
\text { Entrustment }\end{array}$ \\
\hline Strong consensus & $75 \%$ agreement in the combination of either & $\geq 75 \%$ agreement in any one level \\
& slightly important/not important or & moderately important/very important \\
Moderate consensus & $50 \%-74.9 \%$ agreement in the combination of & \\
& either slightly important/not important or & $50 \%-74.9 \%$ agreement in any single level \\
moderately important/very important & & $<50 \%$ agreement in any single level \\
& $<5 \%$ agreement in the combination of either &
\end{tabular}




\section{American Journal of Pharmaceutical Education 2019; 83 (10) Article 7501.}

Table 4. Faculty Consensus Results and Rankings for Level of Importance for Entrustable Professional Activities

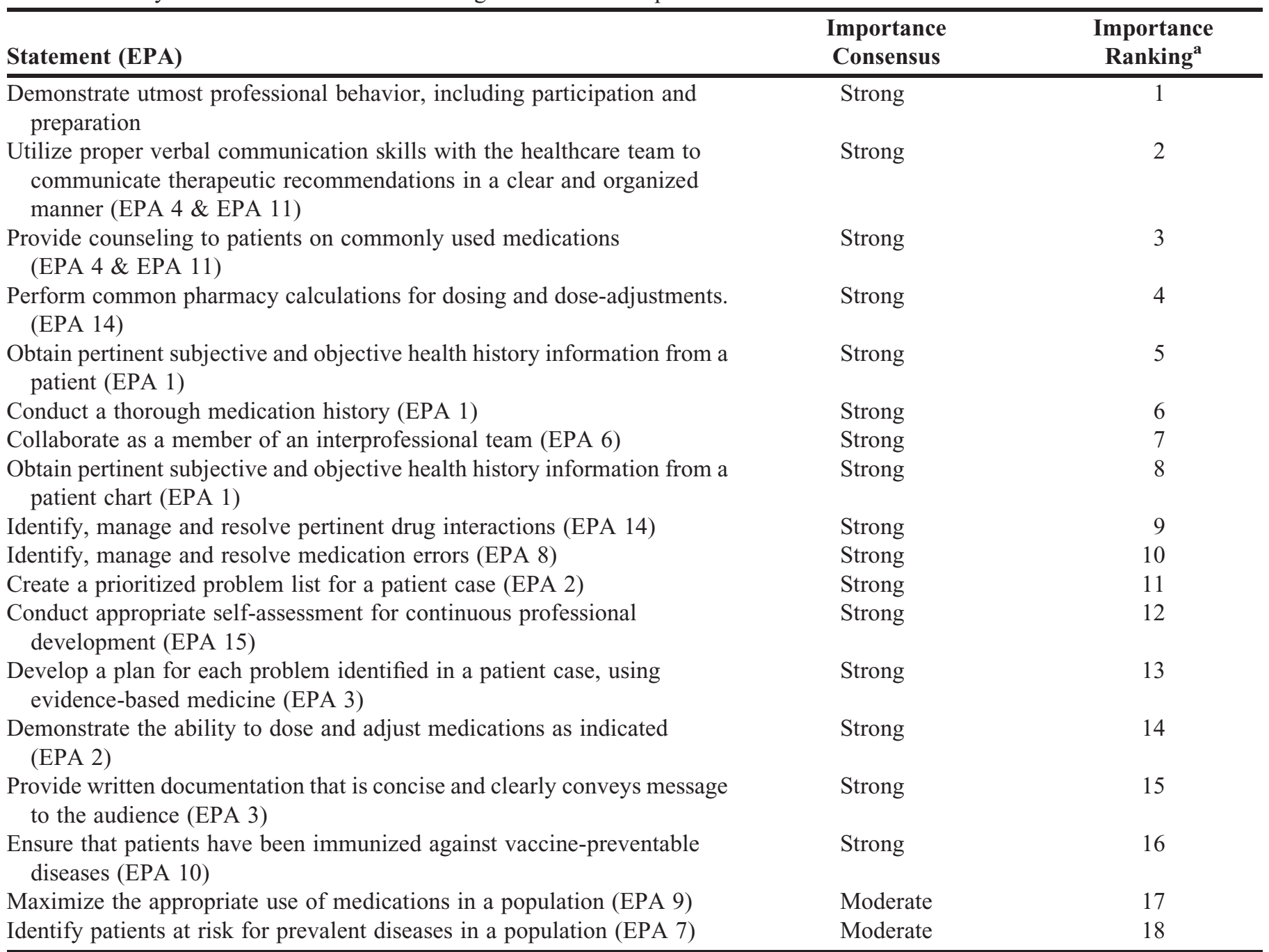

a Importance ranking determined by ordering the percentage score of "very important/moderately important" for each statement. Percentage score ties were ranked according to the majority response between "very important" and "moderately important" for each statement with the tied score

supports the importance of these foundational behaviors necessary to establish trust and perform EPAs. ${ }^{7}$ A strong consensus was observed regarding which EPAs are appropriate for assessing APPE readiness, signaling that selected EPAs could be a logical metric. Of note, faculty members felt that EPAs that directly applied to patient care were more important as a metric to assess APPE readiness, which supports the expectation of students providing patient care on their first day of APPEs. Overall, public health-focused EPAs were seen as less important by faculty respondents. These data parallel those reported in a validation study of EPAs for new pharmacy graduates. ${ }^{12}$ We believe that APPEs may provide greater context for continued learning about public health concepts, therefore it may not be critical to achieving a strong level of entrustability for public health-focused EPAs as a criterion for APPE readiness.
Little consensus was observed on the level of entrustment that is appropriate for EPAs prior to APPEs as demonstrated by the vast majority of EPAs receiving responses in at least four levels of entrustment. This is illustrated by some faculty members responding that APPE students should be able to supervise others in selected EPAs, while others felt comfortable with students only observing the same tasks upon entering APPEs. This wide distribution was somewhat unexpected and sparked several questions. To address the issue of faculty expecting an entrustment Level IV or V prior to APPEs, it seemed appropriate to consider the end goal of APPE training from an EPA standpoint. Although the literature suggests a Level III entrustment for graduates upon graduation, the data provided in this study suggest that many faculty members are not in agreement. ${ }^{3}$ In other words, we are still left asking the question: "What level of entrustment should we 
American Journal of Pharmaceutical Education 2019; 83 (10) Article 7501.

Table 5. Faculty Consensus Results for Levels of Entrustment for Entrustable Professional Activities

\begin{tabular}{|c|c|c|c|c|c|c|c|}
\hline \multirow[b]{2}{*}{ Statement (EPA) ${ }^{a}$} & \multicolumn{6}{|c|}{ Entrustment Level } & \multirow[b]{2}{*}{$\begin{array}{c}\text { Entrustment } \\
\text { Consensus }\end{array}$} \\
\hline & I (\%) & II $(\%)$ & III (\%) & IV (\%) & $V(\%)$ & $\begin{array}{l}\text { Unable to } \\
\text { Rate (\%) } \\
\end{array}$ & \\
\hline $\begin{array}{l}\text { Demonstrate utmost professional behavior, } \\
\text { including participation and preparation }\end{array}$ & 0 & 10.71 & 10.71 & 46.43 & 32.14 & 0 & Little \\
\hline $\begin{array}{l}\text { Utilize proper verbal communication skills } \\
\text { with the healthcare team to communicate } \\
\text { therapeutic recommendations in a clear } \\
\text { and organized manner (EPA } 4 \text { \& EPA 11) }\end{array}$ & 0 & 25 & 25 & 39.29 & 10.71 & 0 & Little \\
\hline $\begin{array}{l}\text { Provide counseling to patients on commonly } \\
\text { used medications (EPA } 4 \text { \& EPA 11) }\end{array}$ & 0 & 10.71 & 53.57 & 28.57 & 7.14 & 0 & Moderate \\
\hline $\begin{array}{l}\text { Perform common pharmacy calculations for } \\
\text { dosing and dose-adjustments. (EPA 14) }\end{array}$ & 0 & 17.86 & 42.86 & 35.71 & 3.57 & 0 & Little \\
\hline $\begin{array}{l}\text { Obtain pertinent subjective and objective } \\
\text { health history information from a patient } \\
\text { (EPA 1) }\end{array}$ & 3.57 & 14.29 & 67.86 & 14.29 & 0 & 0 & Moderate \\
\hline $\begin{array}{l}\text { Conduct a thorough medication history } \\
\text { (EPA 1) }\end{array}$ & 0 & 32.14 & 53.57 & 10.71 & 3.57 & 0 & Moderate \\
\hline $\begin{array}{l}\text { Collaborate as a member of an } \\
\text { interprofessional team (EPA 6) }\end{array}$ & 0 & 17.86 & 35.71 & 39.29 & 7.14 & 0 & Little \\
\hline $\begin{array}{l}\text { Obtain pertinent subjective and objective } \\
\text { health history information from a patient } \\
\text { chart (EPA 1) }\end{array}$ & 3.57 & 10.71 & 60.71 & 21.43 & 3.57 & 0 & Moderate \\
\hline $\begin{array}{l}\text { Identify, manage and resolve pertinent drug } \\
\text { interactions (EPA 14) }\end{array}$ & 0 & 32.14 & 50 & 17.86 & 0 & 0 & Moderate \\
\hline $\begin{array}{l}\text { Identify, manage and resolve medication } \\
\text { errors (EPA 8) }\end{array}$ & 3.57 & 46.43 & 42.86 & 7.14 & 0 & 0 & Little \\
\hline $\begin{array}{l}\text { Create a prioritized problem list for a patient } \\
\text { case (EPA 2) }\end{array}$ & 0 & 28.57 & 42.86 & 28.57 & 0 & 0 & Little \\
\hline $\begin{array}{l}\text { Conduct appropriate self-assessment for } \\
\text { continuous professional development } \\
\text { (EPA 15) }\end{array}$ & 0 & 10.71 & 32.14 & 46.43 & 10.71 & 0 & Little \\
\hline $\begin{array}{l}\text { Develop a plan for each problem identified in } \\
\text { a patient case, using evidence-based } \\
\text { medicine (EPA 3) }\end{array}$ & 0 & 46.43 & 32.14 & 17.86 & 3.57 & 0 & Little \\
\hline $\begin{array}{l}\text { Demonstrate the ability to dose and adjust } \\
\text { medications as indicated (EPA 2) }\end{array}$ & 0 & 42.86 & 35.71 & 21.43 & 0 & 0 & Little \\
\hline $\begin{array}{l}\text { Provide written documentation that is } \\
\text { concise and clearly conveys message to } \\
\text { the audience (EPA 3) }\end{array}$ & 0 & 25 & 46.43 & 21.43 & 7.14 & 0 & Little \\
\hline $\begin{array}{l}\text { Ensure that patients have been immunized } \\
\text { against vaccine-preventable diseases } \\
\text { (EPA 10) }\end{array}$ & 0 & 17.86 & 50 & 21.43 & 7.14 & 3.57 & Moderate \\
\hline $\begin{array}{l}\text { Maximize the appropriate use of medications } \\
\text { in a population (EPA 9) }\end{array}$ & 3.57 & 50 & 28.57 & 17.86 & 0 & 0 & Moderate \\
\hline $\begin{array}{l}\text { Identify patients at risk for prevalent diseases } \\
\text { in a population (EPA 7) }\end{array}$ & 3.57 & 35.71 & 42.86 & 17.86 & 0 & 0 & Little \\
\hline
\end{tabular}

${ }^{a}$ EPA statements are listed in rank order of importance as identified by faculty respondents. Highlighted data indicates the mode for each statement

expect of our students upon graduation from a PharmD program?"

Standards 2016 require that graduates of a PharmD program are practice ready without any further $(\mathrm{eg}$, residency) training. ${ }^{1}$ If practice-readiness is the expectation upon graduation, it may be unrealistic to expect supervision of new graduates to be available in all practice sites. Recognizing that approximately $57 \%$ of pharmacists 


\section{American Journal of Pharmaceutical Education 2019; 83 (10) Article 7501.}

practice in community pharmacy settings, new graduates often find themselves as the only provider on duty. ${ }^{13}$ Level IV may be the closest supervision that a new graduate may receive in many settings, particularly when one considers practice in different urban or rural geographies. Additionally, new graduates often have technicians or interns staffing pharmacies where they are working, necessitating that new graduates provide supervision and give meaningful feedback to others (Level V) as a standard job expectation. Finally, Level III has been adopted from the medical education model where postgraduate residencies are mandatory, thereby requiring additional supervised teaching and learning over several more years of training. ${ }^{14}$ In pharmacy education, without the capacity or requirement for all graduates to enter a residency program, the expectation of substantial supervised teaching and learning after completion of the PharmD degree is impractical. Therefore, we question the appropriateness of a Level III entrustment threshold as a sufficient minimum for practice-readiness for pharmacists.

Based on the aforementioned limited consensus of APPE-readiness thresholds, plus the frequent expectation of Level III entrustment prior to APPEs, it is not clear whether faculty members at our institution consider Level III entrustment to be a practice-readiness threshold. Therefore, our next step is to build consensus around the level of entrustability we believe is appropriate for practice-ready graduates. Once we determine a level of consensus of entrustability thresholds for new graduates, we must accordingly adjust our expectations for entrustability prior to entering APPEs. In short, the lack of consensus of entrustability thresholds prior to APPEs points to the foundational issue for the profession to clearly define the level of entrustability for a practiceready graduate of a PharmD program. Following the establishment of a consensus on the level of entrustment, our institution intends to use the rank order list to delineate which specific EPAs should first be assessed in the determination of readiness to enter APPEs. Additionally, EPAs alone may not be sufficient to define APPE readiness. Other constructs, such as professionalism, may be worthy of consideration as part of a comprehensive assessment approach.

This study has limitations. First, we surveyed faculty members from a single institution, and published literature on EPAs was relatively new at the time the survey was conducted. While the number of respondents was small and responses were collected in 2017, this early assessment data serves as a foundation for other schools and colleges of pharmacy to conduct similar assessment efforts to build consensus around APPE-readiness thresholds leading to appropriate entrustability of practice-ready graduates. The results of this study highlight the need for the Academy to devote greater thought to the issue of what constitutes a practice-ready pharmacist.

The following questions remain that may drive future research: What level of entrustment do employers expect following graduation across different practice sectors and geographies? What level of entrustment can our students reasonably attain while in our schools and colleges of pharmacy? How much growth is achievable within an APPE year? If specific sectors of practice require greater than a Level III entrustability upon entry to practice, how do we reconcile the disconnect of only expecting a Level III upon graduation?

\section{CONCLUSION}

This paper quantifies faculty perceptions of the importance of EPAs and the expected level of entrustment that pharmacy students should achieve to determine readiness to enter APPEs. Strong consensus was observed regarding which EPAs are important in the assessment of APPE readiness. Therefore, EPAs offer a useful framework for assessing APPE readiness. However, little consensus was observed related to level of entrustability. Lacking consensus of a threshold of entrustability prior to APPEs suggests that the Level III entrustability threshold for practice readiness in the literature is not universally supported. Furthermore, the authors question if a Level III entrustability threshold for practice readiness is aligned with employers' expectations of graduates to practice independently in certain settings without additional residency training. In order for EPAs to achieve the intended outcome of advancing both pharmacy education and the practice of pharmacy, the questions posed need to be addressed and consensus within the profession must be built.

\section{REFERENCES}

1. Accreditation Council for Pharmacy Education (ACPE). Accreditation standards and key elements for the professional program in pharmacy leading to the doctor of pharmacy degree ("Standards 2016"). Published February 2015. https://www.acpeaccredit.org/pdf/Standards2016FINAL.pdf. Accessed December 27, 2019.

2. Accreditation Council for Pharmacy Education. Guidance for the accreditation standards and key elements for the professional program in pharmacy leading to the doctor of pharmacy degree ("Guidance for Standards 2016"). https://www.acpe-accredit.org/pdf/ GuidanceforStandards2016FINAL.pdf. Accessed December 27, 2019.

3. Haines ST, Gleason BL, Kantorovich A, et al. Report of the 20152016 academic affairs standing committee. Am J Pharm Educ. 2016;80(9):Article S20. 


\section{American Journal of Pharmaceutical Education 2019; 83 (10) Article 7501.}

4. Haines ST, Pittenger AL, Stolte SK, et al. Core entrustable activities for new pharmacy graduates. Am J Pharm Educ. 2017;81(1):Article S2.

5. Medina MS, Plaza CM, Stowe CD, et al. Center for the Advancement of Pharmacy Education 2013 educational outcomes. Am J Pharm Educ. 2013;77(8):Article 162.

6. Wiggins G., McTighe J. Understanding by Design. 2nd ed. Alexandria, VA: Association for Supervision and Curriculum Development; 2008.

7. Pittenger AL, Chapman SA, Frail CK, et al. Entrustable professional activities for pharmacy practice. Am J Pharm Educ. 2016;80(4):Article 57.

8. Pittenger AL, Copeland DA, Lacroix M, et al. Report of the 20162017 academic affairs standing committee. Am J Pharm Educ. 2017;81(5):Article S4.

9. Riskin J, Henriksen JA, Barnett SG. Experiences with curricular mapping and summative assessments in patient care laboratory sequences. Presented at: Pharmacy Education 2017. American
Association of Colleges of Pharmacy Annual Meeting; 2017 July 1519; Nashville, TN.

10. DeVellis RF. Scale Development: Theory and Applications. 4th ed. Los Angeles: SAGE Publications, Inc;2017.

11. Matell, MS, Jacoby, J. Is there an optimal number of alternatives for Likert scale items? Study I: reliability and validity. Educational and Psychological Measurement. 1971;31(3):657-674. https:// doi.org/10.1177/001316447103100307.

12. Haines ST, Pittenger AL, Gleason BL, et al. Validation of the entrustable professional activities for new pharmacy graduates. $\mathrm{Am} J$ Health-Syst Pharm. 2018;75:e661-8.

13. U.S. Department of Labor, Bureau of Labor Statistics. Occupational Outlook Handbook, Pharmacists. https://www.bls.gov/ ooh/healthcare/pharmacists.htm. Accessed December 27, 2019.

14. Association of the American Medical Colleges. Core entrustable professional activities for entering residency: faculty and learners' guide. https://store.aamc.org/downloadable/download/sample/ sample_id/66/. Published 2014. Accessed December 27, 2019. 